\title{
Caracterizando Questões de Química em Processos Avaliativos de Larga Escala: Uma Análise Comparativa
}

\section{Characterizing Questions of Chemistry in Large Scale Evaluative Processes: A Comparative Analysis}

\author{
Fabiele Cristiane Dias Broietti ${ }^{\circledR}$ Brasil \\ Ourides Santin Filho Brasil \\ Marinez Meneguello Passos ${ }^{(0)}$ Brasil
}

Neste artigo trazemos os resultados de uma pesquisa que buscou evidenciar as relações de natureza didático-pedagógicas e avaliativas na área de Química, tendo por base de estudo questões de Química de um vestibular e do ENEM. Esses exames foram considerados, pois possibilitam o acesso ao Ensino Superior. Para a análise das questões assumimos os procedimentos das análises textuais e orientamos nossas interpretações segundo quatro critérios: conteúdos químicos; competências/habilidades; aspectos contextuais e aspectos estruturais. Com a análise das questões e com base nos documentos oficiais, identificamos que as questões do ENEM contemplam tópicos relacionados a aplicações cotidianas do conhecimento científico e a problemas sociais e ambientais que não encontram correspondentes explícitos no programa do vestibular. As competências e habilidades são exigidas de forma mais ampla e diversificada no ENEM. No que diz respeito aos contextos, foram constatadas diferenças significativas nas questões desses dois exames, enquanto a maioria das questões do ENEM apresenta algum tipo de contexto, privilegiando principalmente problemas socioambientais e questões relacionadas à tecnologia, $40 \%$ das questões do exame vestibular não fazem referência a qualquer contexto. Quanto à estrutura das questões, notamos que $50 \%$ das questões, em ambos os exames, apresentam algum tipo de recurso gráfico, no entanto, no ENEM há uma maior diversidade.

Palavras-chave: avaliação; ENEM; química; vestibular.

In this paper, we present the results of a research that sought to evidence the relationships of didactic-pedagogic and evaluative nature in the Chemistry area, based on the study of chemistry questions of a vestibular and the ENEM. These examinations were considered, since they allow access to university. For the analysis of the questions, we assume the procedures of the textual analyzes and orient our interpretations according to four criteria: chemical contents; competencies/skills; contextual aspects and structural aspects. From the analysis of the questions and based on the official documents, we identified that the ENEM questions contemplate topics related to daily applications of 
scientific knowledge, and social and environmental problems that do not find explicit correspondents in the vestibular program. Competencies and skills are required in a broader and more diversified form in ENEM. Regarding the contexts, there were significant differences in the questions of these two exams, while most ENEM issues present some kind of context, mainly focusing on socio-environmental problems and questions related to technology, $40 \%$ of the vestibular exam questions do not refer to any context. About the structure of the questions, we noticed that $50 \%$ of the questions, in both examinations, present some type of graphical resource, however, in the ENEM there is a greater diversity.

Keywords: evaluation; ENEM; chemistry; vestibular.

\section{Introdução}

O ensino superior no Brasil tem sofrido uma expansão do número de vagas nos últimos anos, com distintas possibilidades de acesso. Tal demanda universitária pode ser justificada pelo aumento da procura dos estudantes de escolas públicas, bem como por grupos diversificados de inclusão (Krasilchik, 2008). Em resposta a esses acontecimentos, além da ampliação do número de vagas nas universidades públicas e de mudanças na forma de ingresso, destaca-se também a concessão de bolsas para estudantes de universidades privadas.

Nos últimos 10 anos (2004-2014) as matrículas nos cursos de graduação dobraram, passando de 3,5 para 7 milhões de estudantes. No período 2009-2012, as matrículas cresceram $15,4 \%$. Os dados mostram também que as instituições de ensino superior (IES) privadas têm uma participação de $71 \%$ no total de matrículas de graduação (INEP, 2014).

Segundo dados do Censo da Educação Superior (INEP, 2014), em 2012 ingressaram 2.747.008 estudantes em cursos de graduação revelando um aumento de $17,1 \%$ em relação a 2011, com uma notável expansão percentual de ingressos nos cursos de educação a distância $(\mathrm{EaD})$, sendo que as instituições privadas respondem por 80,05\% desse total, seguidas das federais com $12,2 \%$, estaduais com $5,5 \%$, e municipais com $2,2 \%$. Do total de 1.970 .392 ingressos por processos seletivos em cursos de graduação presencial, 399.988 entraram por meio do Exame Nacional do Ensino Médio (ENEM), em instituições que o utilizaram, total ou parcialmente, em seus processos seletivos. $\mathrm{O}$ total mencionado representa $20,2 \%$ dos ingressos.

Comparativamente a 2010 (INEP, 2012), os dados do Censo demonstram que a utilização do exame é ampliada em todas as categorias administrativas: nas IES federais, de $31,7 \%$, em 2010, para $51,6 \%$ do total de ingressos por processo seletivo, em 2011; nas IES privadas, de $13,7 \%$ para $16,4 \%$; nas IES estaduais, de $1,9 \%$ para $4,9 \%$ e, nas IES municipais, de $2,4 \%$ para $4,1 \%$.

As universidades possuem autonomia e podem optar entre distintos processos de seleção. Caso escolham utilizar o ENEM como processo seletivo, podem adotá-lo em 
diferentes formatos: como fase única, com o sistema de seleção unificada (SiSU'); como primeira fase do vestibular; combinado com o vestibular da instituição; como fase única para as vagas remanescentes do vestibular; ou ainda utilizar as notas do ENEM em um processo próprio de seleção, sem utilizar o SiSU.

A Universidade Estadual de Londrina passou a adotar, a partir do ano de 2009, dois instrumentos avaliativos compondo o processo de seleção para ingresso nos cursos de graduação. Até o ano de 2008, o Vestibular era o único processo de seleção adotado, mas a partir de 2009 a nota do ENEM começou a ser utilizada para preenchimento das vagas remanescentes ${ }^{2}$ do Vestibular UEL.

Frente a essa situação, propusemo-nos a investigar as questões de Química desses exames segundo quatro critérios: os conteúdos químicos; as competências/habilidades; os aspectos contextuais; e os aspectos estruturais, a fim de pesquisar a existência e as relações de natureza didático-pedagógicas e avaliativas na área de Química que possibilitam o acesso ao Ensino Superior na UEL.

Dessa situação provêm algumas questões que serviram como balizadoras desta investigação. O que estes exames avaliam em termos de conteúdos químicos, competências e habilidades e quais contextos e recursos são utilizados no enunciado das questões desses exames? 2) O que há de semelhante e/ou diferente nas questões que compõem estes exames em relação aos aspectos citados na questão anterior?

Nessa perspectiva, a análise das questões dessas provas, tendo em vista os critérios estabelecidos, contribuiu para uma caracterização mais detalhada das práticas avaliativas que são utilizadas para selecionar estudantes interessados em seguir uma carreira acadêmica.

\section{Avaliações em larga escala}

As avaliações em larga escala buscam informar o que alunos, em diferentes séries, sabem e são capazes de fazer em um determinado momento e acompanhar sua evolução ao longo dos anos. Em consonância, não é seu objetivo fornecer informações individuais e personalizadas sobre alunos ou escolas. Normalmente, as avaliações são organizadas a partir de uma matriz de referência e são aplicadas de forma padronizada para um grande número de pessoas (Klein e Fontanive, 1995).

No Brasil, conforme Werle (2010), as avaliações externas em larga escala com foco na educação básica são realizadas por diferentes instâncias de governo e se caracterizam por serem planejadas, implementadas e terem seus dados interpretados e divulgados

1 O Sistema de Seleção Unificada (SiSU) é um sistema informatizado, gerenciado pelo Ministério da Educação (MEC), no qual instituições públicas de ensino superior oferecem vagas para candidatos participantes do ENEM. O estudante pode escolher até duas opções de curso, podendo alterá-las durante as inscrições. As Universidades que aderem ao SiSU podem atribuir alguns critérios específicos. Há também uma nota de corte, sendo essa a menor nota para ficar entre os selecionados de um curso, com base no número de vagas e do total de inscritos. Os candidatos são então selecionados com base na nota do ENEM, dentro do número de vagas de cada curso. Disponível em http://sisu.mec.gov.br

2 São consideradas remanescentes as vagas em curso e turno para as quais não existam candidatos classificados a convocar (Resolução CEPE No 0102/2009, Art. 10, parágrafo $1^{\circ}$ ). 
por agências externas.

É notável que nos últimos anos a demanda pela qualidade do ensino e a preocupação em avaliar os sistemas educacionais têm conduzido a avaliação como um instrumento que deve oferecer subsídios para o planejamento, elaboração, reformulação e monitoramento de políticas públicas da educação no Brasil.

A importância de estudar estas avaliações impõe-se no cenário educacional pela exigência de instrumentos mais precisos para a adequada leitura do ensino nas instituições, aliado ao compromisso com a qualidade da educação e a necessidade de conhecer o público interno e as variáveis externas ao processo educativo.

No entanto, sabe-se que esses modelos de avaliação geram um gigantesco volume de informações e essas acabam, muitas vezes, restringindo-se aos organizadores dos programas, ou, quando muito, aos gestores das escolas. Os educadores, os maiores interessados, não tomam conhecimento dos resultados, os quais, muitas vezes, são de difícil compreensão (Vianna, 2003).

Becker (2010) apresenta algumas críticas com relação às avaliações educacionais em larga escala, destacando a necessidade de estabelecer uma relação entre a avaliação e a ação, a falta de unidade entre os atores do sistema educacional e os modelos de divulgação dos resultados. A autora reforça que, embora o Brasil tenha avançado na coleta de dados e nos sistemas de avaliação, ainda é preciso construir mecanismos para que os resultados sejam utilizados por gestores e professores de modo a melhorar a qualidade do ensino oferecido.

Fica evidente que existe o desafio de construir a relação entre a avaliação e a sala de aula, para que os exames não fiquem apenas com a função de traçar diagnósticos e que possam, de fato, contribuir para o aperfeiçoamento do sistema educacional. Nesse contexto, torna-se fundamental a realização de pesquisas que tenham como objeto de estudo investigar essas avaliações, tanto em termos dos resultados oriundos da sua aplicação quanto das características das questões que compõem estes exames.

\section{Os exames em análise}

O ENEM é uma avaliação de âmbito nacional, de caráter voluntário, criado pelo Instituto Nacional de Estudos e Pesquisas Educacionais Anísio Teixeira (INEP) e aplicado pela primeira vez em 1998. Teve origem na Lei de Diretrizes e Bases da Educação Nacional - LDB (Lei no 9.394/96 de 20 de dezembro de 1996, Lei de Diretrizes e Bases da Educação Nacional, 1996), que introduziu importantes inovações conceituais e organizacionais às Diretrizes Curriculares Nacionais do Ensino Médio (DCNEM) (Resolução CEB no 3 de 26 de junho de 1998), que preconizam uma reorganização curricular em áreas do conhecimento.

Dentre os documentos que servem como referência para a compreensão do ENEM, e que também foram elaborados pelo Ministério da Educação - MEC, estão os Parâmetros Curriculares Nacionais do Ensino Médio (PCNEM) (MEC, 2000); as Orientações Curriculares Nacionais do Ensino Médio (OCNEM) (MEC, 2006) e as 
Diretrizes Curriculares Nacionais da Educação Básica (DCNEB) (MEC, 2013).

Podem participar do exame estudantes que estão concluindo ou que já concluíram o Ensino Médio em anos anteriores, tratando-se de um exame anual. A prova do ENEM é aplicada em todo o território nacional. Até o ano de 2008 era realizada em apenas um dia; composta por uma redação e 63 questões de múltipla escolha relacionadas a 5 competências e 21 habilidades.

Em maio de 2009, o MEC anunciou mudanças no ENEM. A prova continuava sendo de caráter voluntário, mas a sua estrutura foi alterada. Ela passou a ser realizada em dois dias, composta por uma redação e 180 questões de múltipla escolha, divididas em áreas do conhecimento que abarcam determinados componentes curriculares. No primeiro dia, a prova constitui-se de 45 questões das áreas de Ciências da Natureza e suas Tecnologias (CNT) - Biologia, Física e Química, e 45 questões das áreas de Ciências Humanas e suas Tecnologias (CHT) - Filosofia, Geografia, História e Sociologia. No segundo dia, a prova contém 45 questões das áreas de Linguagens, Códigos e suas Tecnologias (LCT) - Português, Literatura, Língua Estrangeira, Artes e Educação Física, 45 questões de Matemática e suas Tecnologias (MT) - Matemática, e uma redação.

Com a reestruturação do ENEM lançou-se, como principais objetivos: “[...] democratizar as oportunidades de acesso às vagas federais de Ensino Superior, possibilitar a mobilidade acadêmica e induzir a reestruturação dos currículos do Ensino Médio" (INEP, 2009). Dessa forma, as informações obtidas a partir dos resultados do ENEM podem ser utilizadas para acompanhamento da qualidade do Ensino Médio no país. Para além do acompanhamento, podem suscitar impactos na implementação de políticas públicas, na criação de referência nacional para o aperfeiçoamento dos currículos do Ensino Médio, no desenvolvimento de estudos e indicadores sobre a educação brasileira e no estabelecimento de critérios de acesso do participante a programas governamentais como o PROUNI ${ }^{3}$, SiSU e FIES ${ }^{4}$.

A certificação é mais uma possibilidade que o exame oferece. Os participantes maiores de 18 anos que ainda não terminaram a escolarização básica podem participar do ENEM e pleitear a certificação no Ensino Médio junto a uma das instituições que aderem ao processo - Secretarias Estaduais de Educação, Institutos Federais e Centros Federais -, conforme Portaria normativa no 4, de 11 de fevereiro de 2010 (MEC, 2010).

A Universidade Estadual de Londrina (UEL) foi criada em 1970, com a junção de cinco faculdades: Direito; Filosofia, Ciências e Letras; Odontologia; Medicina; Ciências Econômicas e Contábeis. Recebe anualmente cerca de 21.000 inscritos para realizar o Vestibular-UEL e conta com um órgão responsável exclusivamente pela sua organização, a Comissão Permanente de Seleção (COPESE), vinculada à Coordenadoria de Processos Seletivos (COPS).

3 O Programa Universidade para Todos concede bolsas de estudo integrais e parciais (50\%) em instituições privadas de Ensino Superior, em cursos de graduação e sequenciais de formação específica, a estudantes brasileiros sem diploma de nível superior.

4 O Fundo de Financiamento Estudantil é um programa destinado a financiar a graduação na educação superior de estudantes matriculados em instituições não gratuitas. 
Os candidatos são selecionados segundo critérios de avaliação de desempenho no vestibular, que ocorre anualmente em 2 fases. Na primeira, os vestibulandos são submetidos a uma prova de conhecimentos gerais, com 60 questões objetivas e de múltipla escolha, envolvendo conteúdos de Artes, Biologia, Filosofia, Física, Geografia, História, Matemática, Química e Sociologia.

A segunda fase do Vestibular-UEL ocorre em três dias para os candidatos aos cursos que têm prova de habilidade específica e, em dois dias, para os demais cursos. No primeiro dia da 2a fase os alunos realizam prova de Redação, Língua Portuguesa, Literaturas Brasileira e Portuguesa e Língua Estrangeira. No segundo dia todos os candidatos são submetidos à prova de conhecimentos específicos: duas disciplinas selecionadas pelas comissões dos cursos de graduação entre Artes, Biologia, Filosofia, Física, Geografia, História, Língua Portuguesa, Literatura Brasileira e Portuguesa, Matemática, Química e Sociologia. Essa prova é composta de 40 questões objetivas (múltipla escolha), 20 questões de cada disciplina selecionada para o curso.

A partir do ano de 2011 ocorreram mudanças na 2a fase do vestibular: a prova de Redação passou a exigir, no mínimo, 2 textos e, no máximo, 4 textos, contemplando distintos gêneros textuais. A prova de Conhecimentos Específicos passou a ser constituída de 12 questões discursivas, 4 de cada uma das disciplinas desenvolvidas no Ensino Médio, como estabelecidas nas OCNEM e nas Diretrizes Curriculares da Educação Básica do Estado do Paraná, de acordo com os programas a serem definidos no Manual do Candidato.

A partir do Vestibular-UEL-2010, a nota do resultado do ENEM passou a ser aproveitada pela instituição para preenchimento das vagas remanescentes do vestibular, em fase única, para efeito exclusivo de classificação.

Segundo a Resolução CEPE No 0250/2009, fica a cargo da Coordenadoria do Vestibular-UEL o planejamento e a operacionalização da seleção para as vagas remanescentes, mediante classificação dos candidatos por meio do Boletim Individual de Resultados do ENEM. Não há sistema de cotas para preenchimento dessas vagas. As vagas remanescentes do Vestibular são divulgadas em endereço eletrônico específico. Findo o prazo determinado para as inscrições, as vagas que não forem preenchidas são ofertadas para Portadores de Diploma de Curso Superior (PDCS).

No ato da inscrição, o candidato precisa informar os dados de sua inscrição no ENEM, e se inscrever para um único curso, turno e habilitação. A classificação dos candidatos é realizada com base nos resultados das provas objetivas do ENEM e por ordem decrescente dos resultados. Para fins de classificação, no Vestibular-UEL-2010 foram considerados os resultados iguais ou superiores a $60 \%$ do total de acertos das questões objetivas. Nos vestibulares de 2011, 2012 e 2013 poderiam concorrer às vagas estudantes que tivessem obtido resultado igual ou superior a 500 pontos na média das notas das quatro provas objetivas, e não zerado nenhuma delas. 
O número de vagas a serem preenchidas com aproveitamento da nota do ENEM, para os vestibulares 2010 a 2014, é apresentada na Tabela 1.

Tabela 1. Vagas totais destinadas a aproveitamento pela nota do ENEM

\begin{tabular}{ccccc}
\hline Vestibular 2010 & Vestibular 2011 & Vestibular 2012 & Vestibular 2013 & Vestibular 2014 \\
\hline 187 & 85 & 445 & 441 & 578 \\
\hline
\end{tabular}

Fonte: Copese, 2014.

No que diz respeito às vagas destinadas ao Curso de Licenciatura em Química, segue, na Tabela 2, a quantidade de estudantes inscritos no vestibular, a quantidade de estudantes aprovados na 1a fase, aprovados na 2a fase, de estudantes que confirmaram matrícula e dos que foram convocados pelo ENEM.

Tabela 2. Quantidade de estudantes inscritos, aprovados e convocados para ingresso no curso de Licenciatura em Química da UEL

\begin{tabular}{lccc}
\hline Situação & Vestibular 2012 & Vestibular 2013 & Vestibular 2014 \\
\hline Inscritos no Vestibular-UEL & 83 & 77 & 76 \\
\hline Aprovados na $1^{\text {a }}$ Fase & 59 & 64 & 65 \\
\hline Aprovados na 2 $2^{\text {a }}$ Fase & 22 & 10 & 10 \\
\hline Confirmaram matrícula & 16 & 8 & 8 \\
\hline Convocados pelo ENEM & 24 & 32 & 32 \\
\hline
\end{tabular}

Fonte: Copese, 2014.

Nesse sentido observa-se que, por três anos consecutivos, o curso de Licenciatura em Química recebeu estudantes ingressantes de distintos processos seletivos, com destaque para estudantes oriundos do ENEM.

\section{Encaminhamento Metodológico}

Esta pesquisa, de natureza qualitativa, foi desenvolvida segundo os procedimentos da análise textual com ênfase nos critérios da Análise de Conteúdo e da Análise Textual Discursiva, apresentados por Bardin (2011) e por Moraes e Galiazzi (2011). Como corpus investigativo foram selecionadas as questões de Química do ENEM relativas aos anos de $2009,2010,2011$ e 2012. Essa escolha se justifica pelo fato de esse exame ter sofrido uma reestruturação em seu formato a partir do ano de 2009, com a finalidade de servir como processo unificado de ingresso nas Instituições Federais de Ensino Superior e de ter se tornado um instrumento de indução da reestruturação dos currículos do Ensino Médio. $O$ fato de a nota do ENEM ser utilizada para preenchimento de vagas remanescentes no Vestibular-UEL a partir daquele ano legitima também nossa escolha pelos anos dos vestibulares que foram analisados, a saber, os de 2010, 2011, 2012 e 2013.

5 Para esses Vestibulares os candidatos deveriam apresentar a nota equivalente ao resultado do ENEM 2009, 2010, 2011, 2012 e 2013, respectivamente. 
Compuseram ainda os materiais para a realização da pesquisa: os programas das provas, os documentos oficiais voltados aos processos avaliativos disponíveis em sítios governamentais ou da própria instituição, além de legislações brasileiras, diretrizes curriculares, parâmetros, relatórios técnicos, resoluções e demais orientações que contribuem para o entendimento do assunto.

Foram escolhidos quatro critérios para a análise das questões: 1) conteúdos químicos, 2) competências/habilidades, 3) aspectos contextuais e 4) aspectos estruturais. Tomamos como inspiração para a escolha dos critérios o trabalho realizado por Passos, Oliveira e Salvi (2011) e a seguir explicamos, de forma mais detalhada, esses critérios.

Os conteúdos e as competências previstos pelo ENEM, os quais espera-se que sejam do domínio dos estudantes do Ensino Médio, estão descritos em uma Matriz de Referência (MR) ${ }^{6}$. Segundo essa MR, cada uma das áreas de conhecimento possui objetos de conhecimento, assim como habilidades e competências específicas que podem ser exigidas nas questões do referido exame.

No que diz respeito aos conteúdos de Química, há 10 grandes grupos apresentados na MR, abarcando 101 conteúdos específicos, que se referem a conteúdos químicos que fazem parte da grade curricular do Ensino Médio.

Com relação às competências e habilidades, a MR para a área de CNT prevê 8 competências e 30 habilidades. Para melhor compreensão dos termos "competências" e "habilidades", é importante ressaltar que, de acordo com o que está definido no Documento Básico de 2002 do Exame Nacional do Ensino Médio, entende-se que:

[...] competências são as modalidades estruturais da inteligência, ou melhor, ações e operações que utilizamos para estabelecer relações com e entre objetos, situações, fenômenos e pessoas que desejamos conhecer. As habilidades decorrem das competências adquiridas e referem-se ao plano imediato do "saber fazer". Por meio das ações e operações, as habilidades aperfeiçoam-se e articulam-se, possibilitando nova reorganização das competências (INEP, 2002a, p. 5).

Pela avaliação por habilidades e competências investiga-se como o estudante pode, por meio de seus conhecimentos, demonstrar autonomia de julgamento e de ação, de atitudes, valores e procedimentos diante de situações-problema que se aproximam ao máximo das condições reais de convívio social e de trabalho individual e coletivo.

Para o vestibular, quanto ao conteúdo químico exigido nas questões, tomamos como base os conteúdos elencados no manual do candidato. Há 15 grandes grupos compreendendo 84 conteúdos específicos, que se referem a tópicos químicos pertencentes à grade curricular do Ensino Médio.

Como neste exame não há referência a competências e habilidades, para que pudéssemos fazer futuras comparações, classificamos as questões do vestibular quanto às competências e habilidades propostas pelo ENEM.

Dessa forma, assumimos os conteúdos químicos como unidades de busca e, posteriormente, como categoria a priori. Observamos no enunciado e/ou nas alternativas

6 A Matriz encontra-se disponível em http://portal.inep.gov.br/web/enem/sobre-o-enem 
de cada questão termos ou expressões que apresentavam correspondência com os conteúdos estabelecidos.

Para as competências e habilidades utilizamos a classificação já atribuída pelos elaboradores das questões. Essa classificação é divulgada em um link disponível na página do INEP. Para as questões do vestibular utilizamos as competências e habilidades do ENEM como categorias a priori.

Para análise das questões, agregamos aos dois critérios acima mencionados mais dois: os aspectos contextuais e os estruturais utilizados no enunciado das questões. Quanto aos aspectos contextuais, buscamos nesse critério identificar se cada uma das questões estava de fato envolvendo algum tema, independentemente do grau ou profundidade que esse contexto assumia. No que diz respeito ao 40 critério, procuramos investigar quais e com que frequência distintos recursos ${ }^{8}$ apareciam no enunciado das questões, como a utilização de esquemas, estruturas químicas, equações químicas, figuras, gráficos, tabelas, quadros e tirinhas (histórias em quadrinhos e similares).

Foram selecionadas e analisadas 74 questões do ENEM referentes à disciplina de Química (12 compondo a prova do ENEM 2009, 20 compondo a prova do ENEM 2010/1o, 15 compondo a prova do ENEM 2010/2, 15 a prova do ENEM 2011 e 12 questões na prova do ENEM 2012). Embora algumas questões apresentassem caráter interdisciplinar, foi levado em consideração para a seleção, o pertencimento da questão em um dos grupos de conhecimento da Química estabelecidos na MR.

No que diz respeito ao Vestibular-UEL, foram analisadas 48 questões (20 delas compondo as provas do Vestibular-2010, 20 compondo a prova do Vestibular-2011, 4 compondo a prova do Vestibular- $2012^{9}$ e 4 compondo a prova do Vestibular-2013).

As questões de Química de ambos os exames foram classificadas e analisadas uma a uma, como mostram os exemplos a seguir. Uma dessas questões foi a de número 83, do ENEM 2010, apresentada na Figura 1.

7 Disponível em http://portal.inep.gov.br/basica-levantamentos-acessar

8 Entendemos os diferentes recursos utilizados nos enunciados como linguagens possíveis para veicular dados e informações necessárias à compreensão e interpretação dos fenômenos e processos Químicos.

9 A partir do ano de 2011, ocorreram mudanças na 2 a fase do vestibular, propostas pelos colegiados dos cursos e membros da comunidade interna e externa representantes dos segmentos público e privado de ensino. Sugeriuse que a prova de Conhecimentos Específicos fosse formulada com base em três disciplinas, preferencialmente derivadas das macro áreas do conhecimento em que o curso se encontra. Esta prova passou a ser constituída de 12 (doze) questões discursivas, distribuídas entre disciplinas desenvolvidas no Ensino Médio. 


\section{Questão 83}

Ao colocar um pouco de açúcar na água e mexer até a obtençăo de uma só fase, prepara-se uma soluçäo. $O$ mesmo acontece ao se adicionar um pouquinho de sal à água e misturar bem. Uma substância capaz de dissolver o soluto é denominada solvente; por exemplo, a água é um solvente para o açúcar, para o sal e para várias outras substâncias. A figura a seguir ilustra essa citaçäo.

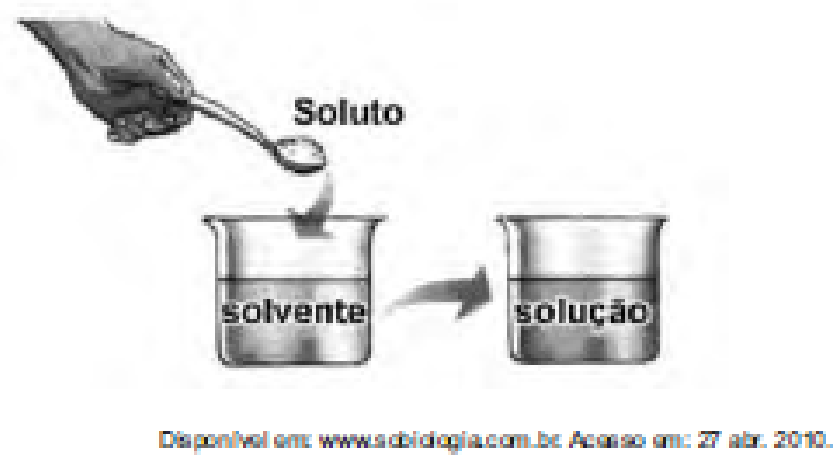

Suponha que uma pessoa, para adoçar seu cafezinho, tenha utilizado $3,42 \mathrm{~g}$ de sacarose (massa molar igual a $342 \mathrm{~g} / \mathrm{mol}$ ) para uma xicara de $50 \mathrm{~m} \ell$ do líquido. Qual é a concentraçäo final, em mollt, de sacarose nesse cafezinho?
(4) 0,02
(B) 0,2
(9) 2
(1) 200
(92000

Figura 1. Questão 83 do ENEM

Fonte: ENEM, 2010.

A questão em pauta aborda o preparo de uma solução a partir da adição de um pouco de açúcar em água e dá outras informações. Ao estudante cabe realizar cálculos e determinar a concentração final da solução em mol/L. Partindo desses encaminhamentos, classificamos essa questão como pertencente ao grupo Água (A) e conteúdo específico concentração das soluções.

A habilidade à qual a questão está relacionada é H25 - Caracterizar materiais ou substâncias, identificando etapas, rendimentos ou implicações biológicas, sociais, econômicas ou ambientais de sua obtenção ou produção. Essa habilidade está vinculada à competência C7 - Apropriar-se de conhecimentos da Química para, em situações-problema, interpretar, avaliar ou planejar intervenções científico-tecnológicas. 
Quanto ao contexto a que esta questão está relacionada, ela foi classificada na Categoria 1 - Alimentos e Bebidas, pois trata de uma situação em que é preciso adoçar o café.

Quanto ao recurso presente no enunciado da questão, notamos a presença de uma figura, evidenciando os componentes de uma solução: soluto e solvente. Sob a perspectiva descrita, a questão 83 do ENEM do ano de 2010 foi classificada, segundo os critérios elencados, conforme o Quadro 1.

Quadro 1. Classificação da questão 83 do ENEM do ano de 2010

\begin{tabular}{|c|c|c|c|c|}
\hline Questão/Ano & Grupo e conteúdo específico & Habilidade e Competência & Contexto & Recurso \\
\hline $83 / 2010$ & $\begin{array}{c}\text { Grupo Água (A): concentração } \\
\text { das soluções }\end{array}$ & $\begin{array}{c}\text { H25 } \\
\text { C7 }\end{array}$ & $\begin{array}{c}\text { Alimentos e } \\
\text { Bebidas }\end{array}$ & Figura \\
\hline
\end{tabular}

Fonte: os autores.

Para o vestibular, elegemos como exemplo a questão de número 2, vestibular 2012, apresentada na Figura 2.

2

Escreva a fórmula estrutural de um composto insaturado $\mathrm{C}_{5} \mathrm{H}_{9} \mathrm{Br}$, que mostra:

a) Isomerismo cis-trans e que não possua atividade óptica.

b) Nenhum isomerismo cis-trans, mas com atividade óptica.

Figura 2. Questão 2 do Vestibular-UEL

Fonte: Vestibular-UEL, 2012.

A questão solicita que seja representada a fórmula estrutural de um composto insaturado de fórmula molecular $\mathrm{C}_{5} \mathrm{H}_{9} \mathrm{Br}$, em duas condições. $\mathrm{O}$ conteúdo químico identificado foi Composto de Carbono (CC) e o conteúdo específico foi - tipos de isomeria.

A habilidade a que esta questão está relacionada é H24 - Utilizar códigos e nomenclatura da química para caracterizar materiais, substâncias ou transformações químicas. Essa habilidade está vinculada à competência C7 - Apropriar-se de conhecimentos da química para, em situações-problema, interpretar, avaliar ou planejar intervenções científico-tecnológicas.

Não identificamos contexto, nem recursos a que tal questão pudesse estar relacionada. Dessa forma a questão número 2 do Vestibular-UEL-2012 foi classificada, segundo os critérios elencados no quadro 2.

O mesmo movimento foi adotado para as demais questões que versam sobre Química e que compõem as provas dos exames investigados. A seguir apresentamos os resultados e as discussões oriundas da comparação entre as questões dos dois exames, para cada um dos critérios estabelecidos. 
Quadro 2. Classificação da questão 2 do Vestibular-UEL-2012

\begin{tabular}{|c|c|c|c|c|}
\hline Questão/vestibular & Grupo e conteúdo específico & Habilidade e Competência & Contexto & Recurso \\
\hline $\begin{array}{c}2 / \text { Vestibular- } \\
\text { UEL-2012 }\end{array}$ & $\begin{array}{c}\text { Grupo Compostos de Carbono } \\
\text { (CC): tipos de isomeria }\end{array}$ & $\begin{array}{c}\text { H24 } \\
\text { C7 }\end{array}$ & --- & --- \\
\hline
\end{tabular}

Fonte: os autores.

\section{Resultados e Discussão: integrando informações}

\section{Os conteúdos químicos}

Na Tabela 3 apontamos a relação entre os conteúdos do ENEM e do vestibular e a porcentagem, em ordem decrescente, de questões acomodadas em tais grupos.

Ao fazer uma análise comparativa, notamos que o ENEM prioriza questões que trazem as relações entre Química, as Tecnologias, a Sociedade e o Meio Ambiente. Isso se traduz pela maior incidência $(20,27 \%)$ das questões relativas ao grupo de conteúdo (RQTSMA). Por outro lado, o vestibular privilegia aspectos mais "conteudistas", destacando a estrutura e o comportamento de substâncias orgânicas e as características das substâncias puras e misturas, na medida em que encontramos maior número de questões (18,75\%) referentes ao grupo (CC) e 16,67\% do grupo (SPM).

Os outros grupos de conteúdos mais abordados nas questões de Química do ENEM foram Compostos de Carbono (17,57\%), seguidos de Representação das Transformações Químicas e Água com 13,51\% do total de questões, enquanto que os grupos de conteúdos mais abordados nas questões do Vestibular-UEL foram os que exigem conhecimentos a respeito das Reações Químicas (10,42\%), seguidos de Ligações Químicas, Termoquímica, Equilíbrio Químico e Oxidação e Redução, com 8,33\% do total de questões em cada um.

Nos exames do ENEM investigados, foram abordados 43 conteúdos específicos de um total de 101 listados na MR. Nos exames vestibulares, de um total de 84 conteúdos específicos listados no manual do candidato, encontramos 37 deles nas questões analisadas - sempre ressalvando que a análise foi feita sobre o conteúdo principal de cada questão. Desse modo, podemos concluir que o ENEM prevê mais conteúdos a serem abordados em suas questões, embora nas questões investigadas tenha exigido apenas $42,5 \%$ dos conteúdos previstos. 
Tabela 3. Grupos de conteúdos químicos e a porcentagem de questões

\begin{tabular}{|c|c|c|c|}
\hline ENEM & $\begin{array}{c}\% \text { de } \\
\text { questões }\end{array}$ & Vestibular-UEL & $\begin{array}{c}\% \text { de } \\
\text { questões }\end{array}$ \\
\hline $\begin{array}{l}\text { Relações da Química com as Tecnologias, a } \\
\text { Sociedade e o Meio Ambiente (RQTSMA) }\end{array}$ & 20,27 & Compostos de Carbono (CC) & 18,75 \\
\hline Compostos de Carbono (CC) & 17,57 & $\begin{array}{l}\text { Substâncias Puras e Misturas } \\
\text { (SPM) }\end{array}$ & 16,67 \\
\hline $\begin{array}{l}\text { Representação das Transformações Químicas } \\
\text { (RTQ) }\end{array}$ & 13,51 & Reações Químicas (RQ) & 10,42 \\
\hline Água (A) & 13,51 & Ligações Químicas (LQ) & 8,33 \\
\hline Transformações Químicas e Energia (TQEn) & 10,81 & Termoquímica (T) & 8,33 \\
\hline Materiais, suas propriedades e usos (MPU) & 9,46 & Equilíbrio Químico (EQ) & 8,33 \\
\hline Transformação Química e Equilíbrio (TQEq) & 6,76 & Oxidação e Redução (OR) & 8,33 \\
\hline Transformação Química (TQ) & 4,05 & Cinética Química (CQ) & 6,25 \\
\hline Energia Química no Cotidiano (EQC) & 2,70 & $\begin{array}{l}\text { Estudo Geral dos Líquidos e } \\
\text { Sólidos (EGLS) }\end{array}$ & 6,25 \\
\hline \multirow[t]{6}{*}{$\begin{array}{l}\text { Dinâmica das Transformações Químicas } \\
\text { (DTQ) }\end{array}$} & 1,35 & $\begin{array}{l}\text { Estudo Geral dos Gases Ideais } \\
\text { (EGGI) }\end{array}$ & 4,17 \\
\hline & & Estrutura Atômica (EA) & 2,08 \\
\hline & & Tabela Periódica (TP) & 2,08 \\
\hline & & $\begin{array}{l}\text { Natureza da Pesquisa Científica } \\
\text { (NPC) }\end{array}$ & 0,00 \\
\hline & & Ácidos e Bases (AB) & 0,00 \\
\hline & & Sistemas Heterogêneos (SH) & 0,00 \\
\hline
\end{tabular}

Fonte: os autores.

No tocante aos conteúdos específicos exigidos nas questões, temos conteúdos semelhantes abordados nos dois exames e conteúdos exclusivos de cada tipo de exame. Nas questões analisadas do ENEM, encontramos conteúdos específicos tais como: número atômico; isótopos; solubilidade e a exigência de conhecimentos químicos relacionados ao ambiente, agricultura, saúde e biocombustíveis que não foram exigidos nas questões analisadas do Vestibular. Por sua vez, as questões analisadas do Vestibular contemplaram os seguintes conteúdos exclusivos: misturas gasosas; lei dos gases ideais; níveis e subníveis de energia; natureza da ligação e propriedades das substâncias; polaridade e simetria; fórmulas empíricas e moleculares.

No que diz respeito aos conteúdos específicos semelhantes que foram abordados em ambos os exames, temos com maior incidência os conteúdos relacionados ao grupo dos compostos de carbono, tais como: identificação de grupos funcionais; reações, características e propriedades dos compostos de carbono e isomeria; seguido pelos 
conteúdos balanceamento e cálculo estequiométrico. Foram também contemplados, nas questões dos dois exames analisados, conteúdos específicos relacionados aos conceitos de ácidos e bases como definição, classificação, propriedades, formulação, reações e nomenclatura. Outros três conteúdos também presentes nas questões de ambos os exames foram cálculos termoquímicos; sistemas em equilíbrio químico e reações de oxidação e redução (pilhas e eletrólise).

Muito embora possam ser estabelecidas certas correlações entre os conteúdos específicos abordados, a forma com que eles são solicitados nas questões apresenta diferença. Vejamos o exemplo a seguir em que são abordadas as transformações químicas e energia elétrica e produção de energia elétrica, em uma questão do ENEM, apresentada na Figura 3 e do vestibular-UEL, apresentada na Figura 4.
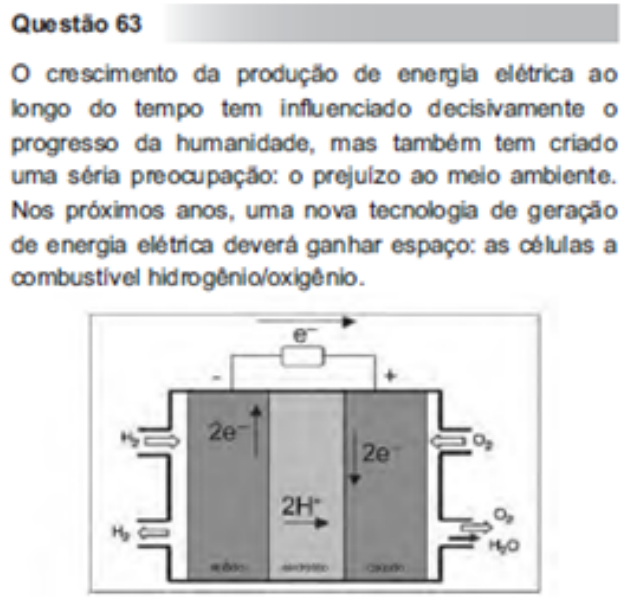

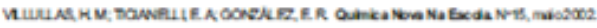

Com base no texto e na figura, a produçăb de energia elétrica por meio de celula a combustivel hidrogênio/ oxbgênio diferencia-se dos processos convendianais porque
(Q) transforma energia química em energia elétrica, sem causar danos ao meio ambiente, porque o principal subproduto formado é a água.

(B) converte a energia química contida nas moléculas dos componentes em energia térmica, sem que ocorra a produçăo de gases poluentes nocivos ao meio ambiente.

๑ transforma energia química em energia elétrica, porém emite gases poluentes da mesma forma que a produçăo de energia a partir dos combustiveis fósseis.

(- Converte energia elétrica proveniente dos combustiveis fósseis em energia química, retendo as gases poluentes produzidos no processo sem alterar a qualidade do meio ambiente.

( ) converte a energia potencial acumulada nas moléculas de água contidas no sistema em energia química, sem que ocorra a produçäo de gases poluentes nocivos ao meio ambiente.

Figura 3. Questão 63 da prova do ENEM

Fonte: ENEM, 2010.

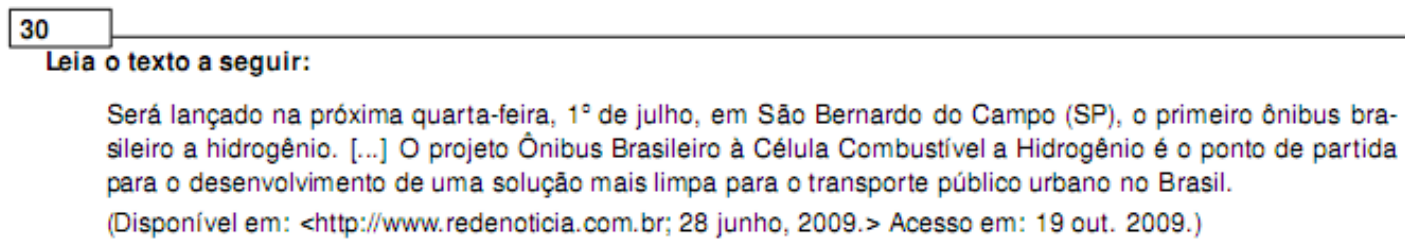

Quanto aos processos quimicos envolvidos na produção de energia elétrica em células de combustiveis a partir do oxigênio e do hidrogênio, é correto afirmar:
a) $O$ estado de oxidação do oxigênio aumenta de zero para +2
b) A equação balanceada para o processo global é $\mathrm{H}_{2}+\mathrm{O}_{2} \rightarrow 2 \mathrm{H}_{2} \mathrm{O}$
c) $\mathrm{O}$ oxigênio é um agente redutor e $\mathrm{o}$ hidrogênio um oxidante.
d) $O$ hidrogênio é reduzido conforme a semi-reação $\mathrm{H}_{2} \rightarrow 2 \mathrm{H}^{+}+2 e^{-}$
(e) reação que ocorre no cátodo é: $\frac{1}{2} \mathrm{O}_{2}+2 \mathrm{H}^{+}+2 e^{-} \rightarrow \mathrm{H}_{2} \mathrm{O}$

Figura 4. Questão número 30 do Vestibular-UEL

Fonte: Vestibular-UEL, 2010. 
Nas questões elencadas aborda-se a produção de energia elétrica por meio de células a combustível hidrogênio e oxigênio. No entanto, na questão de número 63 da prova do ENEM é solicitado ao estudante assinalar a alternativa que diferencie esse processo de produção de energia de outros tipos mais convencionais. Por outro lado, na questão de número 30 do vestibular, pergunta-se sobre os processos químicos envolvidos nessa célula. A alternativa correta a ser assinalada pelo estudante é aquela na qual aparece a reação que ocorre no cátodo dessa célula.

Enquanto na primeira questão o estudante deve, além do conceito envolvido, associar outros aspectos relevantes que envolvam relações sociais, econômicas e ambientais, na segunda basta que o estudante saiba a reação de uma das semirreações que ocorrem na célula.

Questões desse tipo acabam contribuindo pouco para uma educação científica esperada nos últimos tempos, em que se torna evidente a influência e o impacto das ciências em temas de interesse do cotidiano. A menção aos ônibus a hidrogênio apenas parece estabelecer um contexto, uma vez que não há vínculo entre o fato relatado e a questão em si.

Possibilitar aos estudantes è̀ população, de uma forma geral, uma cultura científico -tecnológica que permita compreender a cultura contemporânea, relacionando-a com seu entorno e participando ativamente da sociedade, tornou-se uma necessidade. Diante disso, ensinar Ciências não pode se restringir a priorizar certos tipos de conteúdos conceituais, em detrimento de um ensino mais geral que englobe outros aspectos, como os atitudinais e os procedimentais.

Segundo as OCNEM,

[...] a extrema complexidade do mundo atual não mais permite que o ensino médio seja apenas preparatório para um exame de seleção, em que o estudante é perito, porque treinado em resolver questões que exigem sempre a mesma resposta padrão. O mundo atual exige que o estudante se posicione, julgue e tome decisões, e seja responsabilizado por isso (MEC, 2006, p.106).

Corroborando essas afirmativas, Macedo (1997) pontua que devemos praticar um ensino de Ciências que possibilite aos nossos estudantes a construção de habilidades necessárias para aprender e seguir aprendendo, para que eles possam compreender o mundo em que vivem, integrar-se plena e eficazmente na sociedade como cidadãos críticos, tolerantes, solidários e com capacidade de resolver os problemas que se apresentam na vida cotidiana, além de tomar suas próprias decisões.

Diante desses aspectos, questões que envolvem conteúdos científicos devem apresentar situações-problema que englobem o desenvolvimento de habilidades, possibilitando melhor compreensão do mundo vivido, em contrapartida à mera memorização. De acordo com Broietti (2013), avaliar conhecimentos isolados é pouco interessante e producente, pois os estudantes esquecem-nos, rapidamente, e não demonstram aprendizagem de forma útil. Em contrapartida, avaliar conhecimentos associados a valores, habilidades e experiências acaba por proporcionar aos estudantes 
atitudes como aprender a interpretar, tomar decisões e mobilizar diversos saberes.

No vestibular, os conhecimentos são avaliados de forma isolada, sem apresentar maiores relações com outras situações; já no ENEM percebemos, de forma mais complexa, a interação dos conceitos químicos com outros aspectos de relevância para a formação do cidadão.

Considerando que prezamos por um ensino que privilegie o desenvolvimento de cidadãos socialmente inseridos e com espírito crítico aguçado, o processo de avaliação não pode se limitar a instrumentos que exigem apenas operações cognitivas simples como a memorização; esse tipo de exigência é incompatível com os objetivos da Educação Científica.

Nesse sentido, as DCNEB (MEC, 2013) reforçam que a avaliação proporciona oportunidade de identificar potencialidades e dificuldades de aprendizagem e detectar problemas de ensino; além de subsidiar decisões sobre a utilização de estratégias e abordagens de acordo com as necessidades dos alunos.

Contudo, para isso, "[...] devem ser privilegiadas questões que exigem reflexão, análise ou solução de um problema, ou a aplicação de um conceito aprendido em uma nova situação" (MEC, 2002b, p. 137). Dessa forma, algumas características gerais em termos de conteúdo distinguem as questões do ENEM das questões do Vestibular-UEL.

Dessa forma, no que diz respeito aos conteúdos, podemos afirmar que a MR para o ENEM apresenta acréscimos, principalmente em assuntos ligados a aplicações cotidianas do conhecimento científico e a problemas sociais e ambientais. Tópicos como Relação da Química com a Sociedade, Tecnologia e Meio Ambiente e Energia Química do Cotidiano não encontram correspondentes explícitos nos Programas da disciplina do Vestibular da UEL e, embora haja conteúdos semelhantes exigidos nos dois exames, a maneira como esses conteúdos são solicitados se distingue bastante.

\section{As competências e habilidades}

Na MR do ENEM são elencadas oito competências distribuídas em 30 habilidades que podem ser exigidas nas questões de CNT. Como no vestibular não são explicitadas as definições e nem o entendimento dado a esses termos, realizamos a análise das questões do vestibular a partir das competências e habilidades elencadas na MR do ENEM. No Quadro 3 estão dispostos os percentuais das competências e habilidades exigidas nos dois exames ${ }^{10}$.

Observamos a partir dos dados apresentados no Quadro 3 que no ENEM a competência mais exigida foi a C7 - Apropriar-se de conhecimentos da química para, em situações-problema, interpretar, avaliar ou planejar intervenções científico-tecnológicas -, estando presente em 45,96\% das questões, com predomínio das habilidades H25 - Caracterizar materiais ou substâncias, identificando etapas, rendimentos ou implicações biológicas, sociais, econômicas ou ambientais de sua

10 Algumas competências e suas respectivas habilidades pertencentes à área de CNT são específicas das disciplinas de Física e de Biologia (como, por exemplo, as competências C4 e C8 e as suas habilidades correspondentes) e foram suprimidas. 
obtenção ou produção - e H24 - Utilizar códigos e nomenclatura da química para caracterizar materiais, substâncias ou transformações químicas -, presentes em 16,22\% das questões. Entretanto, todas as competências e habilidades relacionadas no quadro foram contempladas em alguma questão.

Quadro 3. Percentuais das competências e habilidades exigidas nas questões

\begin{tabular}{|c|c|c|c|}
\hline Competências & Habilidades & $\begin{array}{l}\% \text { de } \\
\text { questões do } \\
\text { ENEM }\end{array}$ & $\begin{array}{l}\text { \% de } \\
\text { questões do } \\
\text { Vestibular } \\
\text { UEL }\end{array}$ \\
\hline \multirow{3}{*}{$\begin{array}{l}\mathrm{C} 1 \text { - Compreender as ciências naturais e as } \\
\text { tecnologias a elas associadas como construções } \\
\text { humanas, percebendo seu papel nos processos } \\
\text { de produção e no desenvolvimento econômico e } \\
\text { social da humanidade. }\end{array}$} & $\mathrm{H} 2$ & 5,41 & 0 \\
\hline & $\mathrm{H} 3$ & 1,35 & 0 \\
\hline & $\mathrm{H} 4$ & 2,70 & 0 \\
\hline $\begin{array}{l}\text { C2 - Identificar a presença e aplicar as tecnologias } \\
\text { associadas às ciências naturais em diferentes } \\
\text { contextos. }\end{array}$ & H7 & 1,35 & 0 \\
\hline \multirow{5}{*}{$\begin{array}{l}\text { C3 - Associar intervenções que resultam em } \\
\text { degradação ou conservação ambiental a processos } \\
\text { produtivos e sociais e a instrumentos ou ações } \\
\text { científico-tecnológicas. }\end{array}$} & $\mathrm{H} 8$ & 6,76 & 2,08 \\
\hline & $\mathrm{H} 9$ & 1,35 & 0 \\
\hline & $\mathrm{H} 10$ & 5,41 & 0 \\
\hline & H11 & 1,35 & 0 \\
\hline & $\mathrm{H} 12$ & 5,41 & 0 \\
\hline \multirow{3}{*}{$\begin{array}{l}\text { C5 - Entender métodos e procedimentos próprios } \\
\text { das ciências naturais e aplicá-los em diferentes } \\
\text { contextos. }\end{array}$} & $\mathrm{H} 17$ & 4,05 & 56,25 \\
\hline & $\mathrm{H} 18$ & 5,41 & 12,50 \\
\hline & H19 & 5,41 & 2,08 \\
\hline \multirow{3}{*}{$\begin{array}{l}\text { C6 - Apropriar-se de conhecimentos da física para, } \\
\text { em situações problema, interpretar, avaliar, ou } \\
\text { planejar intervenções científico-tecnológicas. }\end{array}$} & $\mathrm{H} 21$ & 1,35 & 0 \\
\hline & $\mathrm{H} 22$ & 2,70 & 0 \\
\hline & $\mathrm{H} 23$ & 4,05 & 0 \\
\hline \multirow{4}{*}{$\begin{array}{l}\text { C7 - Apropriar-se de conhecimentos da química } \\
\text { para, em situações problema, interpretar, avaliar ou } \\
\text { planejar intervenções científico-tecnológicas. }\end{array}$} & $\mathrm{H} 24$ & 16,22 & 25,00 \\
\hline & $\mathrm{H} 25$ & 16,22 & 0 \\
\hline & $\mathrm{H} 26$ & 6,76 & 0 \\
\hline & $\mathrm{H} 27$ & 6,76 & 2,05 \\
\hline
\end{tabular}

Fonte: os autores.

Já no vestibular, a competência mais exigida foi a C5 - Entender métodos e procedimentos próprios das ciências naturais e aplicá-las em diferentes contextos -, presente em 70,83\% das questões, com predomínio da habilidade H17 - Relacionar informações em diferentes formas de linguagem e representação usadas nas ciências física, química ou biológica, como texto discursivo, gráficos, tabelas, relações matemáticas ou linguagem simbólica -, abordada em $56,25 \%$ das questões. Na sequência, a habilidade mais exigida foi a H18 - Relacionar propriedades físicas, químicas ou biológicas de produtos, sistemas ou procedimentos tecnológicos às finalidades a que se destinam -, compondo $12,50 \%$ das questões. 
No vestibular, as únicas competências exigidas foram as C3, C5 e C7, compreendendo ao todo 5 habilidades. As competências C1, C2 e C6 e suas respectivas habilidades não foram contempladas.

A competência C1 - Compreender as ciências naturais e as tecnologias a elas associadas como construções humanas, percebendo seu papel nos processos de produção e no desenvolvimento econômico e social da humanidade - relaciona-se à habilidade de aceitar o conhecimento científico como uma construção humana. Também, está associada a fatores culturais, históricos e econômicos, ao confronto de interpretações científicas com as do senso comum, e à avaliação de propostas de intervenção do meio ambiente.

A competência C2 - Identificar a presença e aplicar as tecnologias associadas às ciências naturais em diferentes contextos - volta-se para as habilidades de relacionar informações para compreender manuais de instalação e selecionar testes ou parâmetros, tendo em vista a defesa do consumidor e a qualidade de vida.

A competência C6 - Apropriar-se de conhecimentos da física para, em situações-problema, interpretar, avaliar, ou planejar intervenções científico-tecnológicas - pautase na utilização das leis da Física e da Química para interpretar processos naturais, compreender fenômenos decorrentes da interação entre radiação e matéria e avaliar possibilidades de geração, uso ou transformação de energia, apreciando implicações.

Enquanto o ENEM é mais abrangente por considerar em suas questões outros aspectos além dos conceituais, o vestibular se restringe às relações entre diversos tipos de informações e a relacionar propriedades físicas, químicas e biológicas, ou a utilizar códigos e nomenclatura química para caracterizar materiais, substâncias e/ou transformações. O predomínio da competência C5 no vestibular dá ênfase à filosofia de uma Ciência "internalista”, que se justifica pelos seus procedimentos e métodos próprios.

\section{Os contextos exigidos nos exames}

No tocante aos contextos constatamos que há uma distribuição bastante diversa de contextos nos dois exames. Classificamos as questões dentro de categorias de contextos mais ou menos similares. Na Tabela 4 apresentamos os percentuais de questões em cada contexto, para cada exame investigado.

Constatamos que, das 74 questões do ENEM que foram investigadas, apenas uma questão (1,35\% do total da amostra) não apresenta relação com algum tipo de contexto. Por outro lado, 18 questões (39,58 das questões) dos vestibulares não apresentam qualquer contexto, evidenciando o caráter "conteudista" do exame. Essas questões, muitas vezes, nem apresentam enunciado explicativo, apenas a menção para que seja assinalada a alternativa que apresenta a afirmativa correta como exemplificado na questão apresentada na Figura 5. 
Tabela 4. Percentual de questões em cada contexto (para cada tipo de exame)

\begin{tabular}{lcc}
\hline Contexto & \% de questões do ENEM & \% de questões do Vestibular-UEL \\
\hline Alimentos/bebidas & 8,11 & 4,17 \\
\hline Combustíveis & 8,11 & -- \\
\hline Metais & 6,76 & -- \\
\hline Poluição atmosférica & $\mathbf{1 8 , 9 2}$ & 6,25 \\
\hline Água & 5,41 & 8,33 \\
\hline Produção de energia & 4,05 & 6,25 \\
\hline Reciclagem e lixo & 8,11 & -- \\
\hline Saúde & 12,16 & 8,33 \\
\hline Solo & 4,05 & -- \\
\hline Cotidiano & 8,11 & -- \\
\hline Outros & 14,86 & 27,08 \\
\hline Sem contexto & 1,35 & 39,58 \\
\hline
\end{tabular}

Fonte: os autores.

21

Assinale a alternativa correta.

a) Se uma substância apresenta moléculas, ela deve apresentar ligaçōes iônicas.

b) Substâncias como $\circ \mathrm{NaCl}$ são formadas por moléculas pequenas.

c) Substâncias como o $\mathrm{NaCl}$ săo formadas por moléculas pequenas e por muitas ligaçōes iônicas.

(D) Se uma substância apresenta moléculas, ela apresenta ligaçōes covalentes.

e) Substâncias como o NaCl são formadas por muitas ligaçōes covalentes.

Figura 5. Questão número 21 do Vestibular-UEL

Fonte: Vestibular-UEL, 2010

Os contextos utilizados para problematizar os conhecimentos químicos nas questões de Química do ENEM foram bastante variados, com predominância da abordagem de temas ambientais. Entretanto, essa condição não foi observada na análise realizada com as questões de Química dos vestibulares-UEL.

Nesse exame, foram identificadas questões que abordavam contextos variados como, por exemplo: cimento para construções; indústria de fabricação de plástico; proteína verde fluorescente; explosivos; coloração de chama; experimentos; plasma sanguíneo, acidente em curtume, recuperação do brilho de talheres de prata. Dentre as questões que apresentaram o mesmo contexto, assinalamos um maior número de questões $(8,33 \%)$ abordando temáticas relacionadas à Saúde e à Água.

A forma como é utilizado o contexto na elaboração das questões também é intensamente divergente nos dois exames. Enquanto no ENEM o contexto busca de alguma forma contribuir para dar significado ao conhecimento químico abordado, como 
é sugerido nos documentos oficiais (INEP, 2000, 2002b; MEC, 2006), nos vestibulares ele aparece apenas como algo pontual, exemplificando determinada situação, muitas vezes sem relação com o que será solicitado na questão.

A título de exemplo, selecionamos uma questão de cada exame, abordando contextos semelhantes, as quais se integram na categoria Saúde: a questão de número 36 do ENEM 2009, apresentada na Figura 6 e a questão de número 34 do vestibular UEL2011, apresentada na Figura 7.

\section{Questad 36}

O uso de protetores solares em situações de grande exposição aos raios solares como, por exemplo, nas praias, é de grande importância para a saúde. As moléculas ativas de um protetor apresentam, usualmente, anéis aromáticos conjugados com grupos carbonila, pois esses sistemas são capazes de absorver a radiação ultravioleta mais nociva aos seres humanos. A conjugação é definida como a ocorrência de alternância entre ligações simples e duplas em uma molécula. Outra propriedade das moléculas em questão é apresentar, em uma de suas extremidades, uma parte apolar responsável por reduzir a solubilidade do composto em água, o que impede sua rápida remoção quando do contato com a água. De acordo com as considerações do texto, qual das
moléculas apresentadas a seguir é a mais adequada para funcionar como molécula ativa de protetores solares?

Figura 6. Questão 36 da prova do ENEM

Fonte: ENEM, 2009

$\mathrm{Na}$ referida questão, menciona-se a importância do uso de protetores solares no caso de exposição aos raios solares, e se refere à composição e às propriedades das moléculas ativas desses protetores, explicando a função dos produtos inibidores na absorção da radiação ultravioleta. Partindo do texto explicativo, é solicitada ao estudante a identificação da alternativa que apresenta a molécula mais adequada para atuar como molécula ativa dos protetores solares. Há vínculo entre o enunciado da questão e as alternativas dadas.

Com o mesmo contexto - Saúde - temos a questão do vestibular-UEL, apresentada na Figura 7. 
34

A esquizofrenia é uma patologia psiquiátrica caracterizada por perturbaçōes do pensamento, da percepção e do convivio social. A doença de Parkinson é um transtorno neurodegenerativo causado pela perda seletiva de neurônios dopaminérgicos. A dopamina é uma substância que está relacionada com as duas doenças citadas. A fórmula da dopamina é mostrada ao lado.

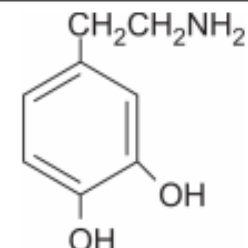

A composição centesimal dos átomos de $\mathrm{C}, \mathrm{H}, \mathrm{O}$ e $\mathrm{N}$ na molécula da dopamina são, respectivamente:

(a) 62,$7 ; 7,3 ; 20,9$ e 9,1

b) 60,$5 ; 9,1 ; 19,0$ e 11,4

c) 43,$8 ; 16,2 ; 8,0$ e 32,0

d) 20,$7 ; 63,0 ; 8,3$ e 8,0

e) 18,$5 ; 60,0 ; 10,4$ e 11,1

Figura 7. Questão número 34 do Vestibular-UEL

Fonte: Vestibular-UEL, 2011.

Nessa questão, são mencionadas algumas patologias e a relação delas com uma substância química específica, a dopamina. É apresentada também a fórmula estrutural da substância e solicitado ao estudante que assinale a alternativa que apresenta a composição centesimal dos átomos que compõem a molécula da dopamina.

Embora as duas questões abordem a temática Saúde, os modos como o contexto é explorado são muito discrepantes. Enquanto na questão do ENEM referente ao uso de protetores solares o estudante necessita do entendimento do texto e das relações entre as moléculas ativas desse fármaco, sua composição e propriedades para resolver a questão, na questão do vestibular, por outro lado, mesmo sem o texto inicial, os estudantes podem calcular as porcentagens de átomos presentes na fórmula da dopamina. A menção às doenças e sua relação com a dopamina serviram apenas como exemplificadoras de onde se pode encontrar essa molécula, mas não como algo fundamental para a resolução da questão.

Nesse sentido, consideramos que o contexto não pode ser pensado apenas como um pretexto para o desenvolvimento dos conhecimentos científicos, uma vez que a significação de conceitos, viabilizada por meio do ensino contextualizado, permite muito mais do que sua aprendizagem, já que possibilita o desenvolvimento cognitivo que capacita os sujeitos a pensar e agir de forma mais consciente no mundo.

Em geral, encontramos nos programas dos vestibulares uma enorme quantidade de conteúdos, com minúcias desnecessárias, que se constituem em uma proposta de currículo bastante divergente daquelas defendidas pela comunidade de pesquisadores em Educação Química, que consideram nos processos de construção do conhecimento escolar a inter-relação dinâmica de conceitos cotidianos e químicos, de saberes teóricos e práticos, não na perspectiva da conversão de um no outro, nem da substituição de um pelo outro, mas pelo diálogo capaz de ajudar no estabelecimento de relações entre conhecimentos diversificados, pela constituição de um conhecimento plural capaz de potencializar a melhoria da vida (Driver et al., 1999). 
Nesse enfoque constatamos que, quanto ao contexto, as diferenças são grandes. A maioria das questões de Química do ENEM apresenta algum tipo de contexto compondo o enunciado da questão, privilegiando, principalmente, aspectos socioambientais e questões relacionadas à tecnologia, o que não é verificado com frequência nas questões do vestibular UEL. No primeiro caso, há ampla articulação entre os enunciados das questões e suas alternativas correspondentes, algo que está ausente no segundo caso. As questões sem contexto envolvem situações imaginárias, irreais, de caráter convencionalmente acadêmico e livresco, que trazem um mínimo de informação para que o aluno compreenda dados numéricos fictícios e aplique em fórmulas (Pacheco, Megid Neto \& Curado, 1996).

Questões com essa característica acabam reforçando o ensino vigente nas escolas, com ênfase na transmissão de conteúdos, na memorização de fatos, símbolos, nomes e fórmulas, deixando de lado a construção do conhecimento científico dos alunos e a articulação entre o conhecimento químico e o cotidiano (Miranda \& Costa, 2007).

\section{Os diferentes tipos de recursos}

Na Tabela 5 apresentamos a quantidade relativa de recursos utilizados no enunciado das questões, em cada um dos exames.

Tabela 5. Quantidade de recursos contemplados em cada exame

\begin{tabular}{lcc}
\hline Recursos & ENEM & UEL \\
\hline Esquema & 2 & 0 \\
\hline Estrutura química & 10 & 6 \\
\hline Equação química & $\mathbf{1 2}$ & 13 \\
\hline Figura & 5 & 4 \\
\hline Gráfico & 3 & 3 \\
\hline Tabela & 4 & 7 \\
\hline Quadro & 4 & 1 \\
\hline Tirinha & 1 & 0 \\
\hline Total & 41 & 34 \\
\hline Total de questões que apresentam algum tipo de recurso & 38 & 27 \\
\hline
\end{tabular}

Fonte: os autores.

Dos recursos mencionados, as equações químicas foram as mais utilizadas nas questões das provas do ENEM, estando presentes em 16,21\% delas, seguidas de estrutura química (13,51\%) e figuras em geral (6,75\%).

Para as questões do vestibular analisadas, destacam-se as equações químicas, tabelas e estruturas químicas, com incidência de $27,08 \%, 14,58 \%$ e $12,5 \%$ respectivamente.

Percebemos, por conseguinte, que as equações químicas foram as mais empregadas, nos dois exames; após elas o ENEM apresenta-nos: estrutura química, 
figura, tabela e quadro. Quanto ao vestibular, utilizou-se tabela e estrutura química, seguidas de figura e gráfico. Por fim, do conjunto de recursos adotados, o ENEM fez uso de esquemas e de tirinhas, o que não ocorreu nos exames vestibulares.

Nesse sentido, assim como a alfabetização científica orienta-se no sentido de proporcionar aos alunos os conhecimentos, habilidades e atitudes que lhes possibilitem compreender e saber utilizar os conhecimentos científicos para se desenvolverem como cidadãos na sociedade, destaca-se a importância da "alfabetização gráfica" que, de acordo com Barquero, Schotz e Reuter (2000), corresponde ao conhecimento sobre as possibilidades de apresentar informações visualmente, por meio de gráficos, desenhos, diagramas e a habilidade de compreender as representações produzidas pelos outros.

Nessa perspectiva, observamos que mais de 50\% das questões dos exames em pauta apresentaram algum tipo de recurso no enunciado da questão, no entanto, no ENEM, todos os tipos considerados (esquema, estrutura química, equação química, figura, gráfico, tabela, quadro e tirinha/história em quadrinhos) foram contemplados, sendo que, no vestibular, não foram encontrados esquemas e tirinhas na composição dos enunciados.

Com as análises realizadas até o momento e afora as diferenças em termos de conteúdos, competências e habilidades, aspectos contextuais e estruturais, vale salientar que estes exames diferem também em termos históricos, de princípios e de propósitos. Apresentamos, no Quadro 4, um comparativo em relação a diversos aspectos. ${ }^{12}$

Quadro 4. Quadro comparativo entre o ENEM e o Vestibular, em termos históricos, de princípios e de propósitos

\begin{tabular}{|l|l|l|}
\hline & ENEM & Vestibular \\
\hline Início & 1998 & 1911 \\
\hline $\begin{array}{l}\text { Objetivo } \\
\text { inicial }\end{array}$ & $\begin{array}{l}\text { Avaliar o desempenho do aluno ao término da } \\
\text { escolaridade básica, para aferir o desenvolvimento } \\
\text { de competências fundamentais ao exercício pleno } \\
\text { da cidadania. }\end{array}$ & $\begin{array}{l}\text { Servir como exame de admissão } \\
\text { para ingresso nos cursos } \\
\text { superiores. }\end{array}$ \\
\hline Documentos & $\begin{array}{l}\text { LDB(1996); } \\
\text { nCNEM(1998); } \\
\text { PCNEM (2000); }\end{array}$ & \\
& $\begin{array}{l}\text { OCEM (2006); } \\
\text { DCNEB (2013). }\end{array}$ & Decretos 8.661 e 8662 $;$ \\
& & \\
\hline
\end{tabular}

11 Decretos promulgados no Governo Hermes da Fonseca, em abril de 1911, que aprovavam, os regulamentos das Faculdades de Medicina e das Faculdades de Direito. Ambos os Decretos estabeleciam, que para matricular-se o candidato deveria apresentar: certidão de idade, provando ter, no mínimo 16 anos, atestado de idoneidade moral, certificado de aprovação no exame de admissão e recibo de taxa de matrícula (Ribeiro Netto, 1985) (grifo nosso). 12 O Decreto 8.659, também de abril de 1911, aprovava a lei Orgânica do Ensino Superior e do Fundamental na República. O artigo 65 deste Decreto estabelecia: "Para concessão da matrícula o candidato passará por um exame que habilite a um juízo de conjunto sobre o seu desenvolvimento intelectual e capacidade para empreender eficazmente o estudo das matérias que constituem o ensino da faculdade" (Ribeiro Netto, 1985). 
Fonte: os autores

Quadro 4. Quadro comparativo entre o ENEM e o Vestibular, em termos históricos, de princípios e de propósitos - continuação

\begin{tabular}{|c|c|c|}
\hline & ENEM & Vestibular \\
\hline $\begin{array}{l}\text { Estrutura da } \\
\text { prova }\end{array}$ & $\begin{array}{l}\text { Até o ano de } 2008 \text { - } 63 \text { questões de múltipla } \\
\text { escolha e uma redação. } \\
\text { A partir do ano de } 2009 \text { - } 180 \text { questões } \\
\text { (divididas em áreas do conhecimento) e uma } \\
\text { redação. }\end{array}$ & $\begin{array}{l}\text { Originalmente - prova escrita em } \\
\text { vernáculo, e uma prova oral sobre } \\
\text { línguas e ciências. } \\
\text { Atualmente - prova com questões } \\
\text { de conhecimentos gerais e } \\
\text { conhecimentos específicos, que } \\
\text { podem ser de múltipla escolha } \\
\text { ou dissertativas e um tipo de } \\
\text { produção textual. }\end{array}$ \\
\hline $\begin{array}{l}\text { Prioriza a } \\
\text { avaliação de: }\end{array}$ & Competência e habilidades. & Conteúdos. \\
\hline $\begin{array}{l}\text { Outros } \\
\text { objetivos }\end{array}$ & $\begin{array}{l}\text { Acompanhar a qualidade do Ensino Médio no } \\
\text { País; } \\
\text { Implementar políticas públicas, na criação de } \\
\text { referência nacional para o aperfeiçoamento dos } \\
\text { currículos do Ensino Médio; } \\
\text { Desenvolver estudos e indicadores sobre a } \\
\text { educação brasileira; } \\
\text { Estabelecer critérios de acesso do participante a } \\
\text { programas governamentais; } \\
\text { Constituir parâmetros para a autoavaliação; } \\
\text { Servir de mecanismo de acesso ao Ensino } \\
\text { Superior; } \\
\text { Outorgar certificação a participantes maiores } \\
\text { de } 18 \text { anos que ainda não terminaram a } \\
\text { escolarização básica. }\end{array}$ & $\begin{array}{l}\text { Selecionar candidatos aptos aos } \\
\text { cursos superiores. }\end{array}$ \\
\hline
\end{tabular}

Fonte: os autores.

Observamos que os exames se originaram em contextos históricos diferentes e, portanto, apresentam características e objetivos bem específicos. O ENEM surgiu na década de 1990, época em que as políticas de avaliação em larga escala foram desencadeadas no Brasil de forma mais intensa.

Diante de iniciativas de avaliação de desempenho dos estudantes realizadas pelo Ministério da Educação (MEC), essas avaliações tinham por objetivo diagnosticar as possíveis insuficiências na aprendizagem dos educandos, assim como o direcionamento das ações pedagógicas, administrativas e financeiras com o intuito de melhorar a qualidade do ensino no país (Schneider, Rostirola, \& Mozz, 2011). 
Por outro lado, o Vestibular surgiu no começo do século XX, ora sob a forma de habilitação, ou seja, visando a verificar a competência dos estudantes para cursos mais avançados, ora sob a forma de classificação, visando a adequar o número de candidatos às vagas existentes (Amauro, 2008). Apesar de estes exames terem passado por reestruturações ao longo dos anos, algumas características originais mantêm-se arraigadas, perdurando nos dias atuais.

\section{Considerações Finais}

Diante das análises realizadas, embora tenham sido encontradas algumas sobreposições em termos de conteúdos químicos, competências e habilidades, contextos e recursos, há algumas diferenças bastante significativas. Enquanto o ENEM se estrutura a partir de princípios mais gerais, com enfoque na formação de um indivíduo cidadão, o vestibular se caracteriza simplesmente como um instrumento de classificação/seleção, sendo visto pelos elaboradores das questões como uma ferramenta para selecionar os alunos para cursos universitários, lançando mão, principalmente, das capacidades dos alunos operarem conteúdos químicos, sem necessariamente ter de vinculá-los a qualquer contexto social.

No entanto, há que se considerar que ambos os exames, além de selecionarem candidatos a níveis superiores de ensino, acabam por influenciar práticas docentes, elaboração de materiais didáticos (livros, apostilas etc.) utilizados pelos professores nos vários níveis de escolarização, que usam questões desses exames como exemplos de atividades escolares (Krasilchik, 2008). No que diz respeito ao currículo, Maldaner (2006) ressalta a influência no Ensino Médio das provas de seleção para o Ensino Superior, uma vez que muitos programas de ensino ou educação são confundidos com programas de seleção ou de concurso. Que professor nunca se deparou, em sala de aula, com a problemática de trabalhar duas metas: preparar o aluno para exames de seleção ao Ensino Superior ou formar o indivíduo cidadão? Duas realidades que têm projetado o professor em sentidos opostos.

Estudos como este trazem informações sobre os conteúdos, temas, habilidades, recursos que estão presentes nesses exames e a forma como os aspectos mencionados são exigidos nos processos avaliativos. O conhecimento dos aspectos constituintes permite adaptações e ajustes no ensino que é promovido nas escolas.

A evidência de determinados conceitos químicos em detrimento de outros não tão solicitados, a exigência de certas habilidades, o uso de temas específicos ou de alguns tipos de recursos e a forma como esses aspectos estão articulados nas questões acabam por provocar tendências educativas que nem sempre correspondem aos promissores objetivos da Educação Química.

Dessa forma, o estudo dos mecanismos de seleção dos alunos para as IES tornase socialmente importante, uma vez que pode influenciar as práticas docentes de todo sistema que o antecede, quando muito, influenciando também os currículos futuros. Essa influência ressalta-se, ainda mais, devido à grande demanda universitária. Os 
fatos supracitados nos levam a constatar que as questões das provas que selecionam os candidatos acabam se constituindo como autênticos orientadores e legitimadores de currículos desenvolvidos por professores em sala de aula.

Mesmo ressaltando a importância das provas, não pretendemos afirmar que apenas a melhoria na qualidade das questões que compõem esses exames modificaria a qualidade do Ensino Médio, isso porque entendemos que essa não é uma luta isolada, de uma disciplina, escola ou universidade. Acreditamos que essas mudanças podem contribuir para a difusão cada vez mais ampla dos resultados das pesquisas educacionais na área de Educação Química, das inovações pedagógicas e para formar o professor cada vez mais agente do seu próprio trabalho pedagógico.

Dos pressupostos descritos, podemos concluir que a UEL adota dois processos com perspectivas diferentes em sua seleção. No entanto, se essas diferenças se fazem evidentes ao longo do Curso de Química e se, ao final desse percurso, os dois tipos de estudantes se tornam um conjunto mais homogêneo, somente estudos posteriores, focados nos acadêmicos, poderão nos responder.

\section{Referências}

Amauro, N. Q. (2008). Os concursos vestibulares das universidades estaduais paulistas e o ensino de Química no nível médio. (Tese de Doutorado em Ciências). Universidade de São Paulo, São Carlos.

Bardin, L. (2011). Análise de Conteúdo. São Paulo: Edições 70.

Barquero, B., Schotz, W., \& Reuter, S. (2000). Adolescents and adult's skills to visually communicate knowledge with graphic. Infancia y Aprendizaje, 90, 71-97.

Becker, F. da R. (2010) Avaliação educacional em larga escala: a experiência brasileira. Revista Iberoamericana de Educación, 53(1), 1-11.

Broietti, F. C. D. (2013) O ENEM, o vestibular e o ensino de química: o caso da Universidade estadual de Londrina. (Tese de Doutorado em Educação para a Ciência e a Matemática), Universidade Estadual de Maringá, Maringá.

Driver, R., Asoko, H., Leach, J, Mortimer, E., \& Scott, P. (1999 ). Construindo o conhecimento científico na sala de aula. Química na Nova Escola, São Paulo, 9, 31-40.

INEP. (2002a). Instituto Nacional de Estudos e Pesquisas Educacionais Anísio Teixeira. Documento Básico do ENEM. (INEP): Brasília.

INEP. (2009). Instituto Nacional de Estudos e Pesquisas Educacionais Anísio Teixeira. Proposta: unificação dos processos seletivos das Instituições Federais de Ensino Superior a partir da reestruturação do Exame Nacional do Ensino Médio (ENEM). Disponível em http://portal.inep.gov.br/c/journal/view_article_ content? groupId $=10157 \&$ articleId $=13157 \&$ version $=1.0$ 
INEP. (2012). Instituto Nacional de Estudos e Pesquisas Educacionais Anísio Teixeira. Brasil. Censo da educação superior: 2010 - resumo técnico. - Brasília: Instituto Nacional de Estudos e Pesquisas Educacionais Anísio Teixeira.

INEP. (2014). Instituto Nacional de Estudos e Pesquisas Educacionais Anísio Teixeira. Censo da educação superior: 2012 - resumo técnico. - Brasília: Instituto Nacional de Estudos e Pesquisas Educacionais Anísio Teixeira.

Klein, R., \& Fontanive, N. S. (1995). Avaliação em larga escala: uma proposta inovadora. Em Aberto, Brasília, 15(66) .

Krasilchik, M. (2008). Prática de Ensino de Biologia (6.ed.). São Paulo: Edusp.

Lei de Diretrizes e Bases da Educação Nacional, Lei n. 9.394, de 20 de dezembro de 1996.

Macedo, B. (1997). La educación cientifica, un aprendizaje accesible a todos. In Proyecto Principal de Educación en América Latina y el Caribe, Santiago, Chile, (pp. 5-7).

Maldaner, O. A. (2006 ). A formação inicial e continuada de professores de Química (3.ed.). Ijuí: Ed. Unijuí.

MEC. (2000). Ministério da Educação, Secretaria de Educação Média e Tecnológica (Semtec). Parâmetros Curriculares Nacionais para o Ensino Médio. Brasília: MEC/Semtec.

MEC. (2002b). Ministério da Educação, Secretaria do Ensino Médio e Tecnológico. PCN+ ensino médio: orientações complementares aos Parâmetros Curriculares Nacionais: Ciências da Natureza, Matemática e suas Tecnologias. MEC/SEMTEC.

MEC. (2006). Ministério da Educação. Brasil, Secretaria de Educação Básica (SEB), Departamento de Políticas de Ensino Médio. Orientações Curriculares para o Ensino Médio. Brasília: MEC/SEB.

MEC. (2013). Ministério da Educação. Diretrizes Curriculares Nacionais Gerais da Educação Básica. Secretaria de Educação Básica. Diretoria de Currículos e Educação Integral.

Miranda, D. G. P, \& Costa, N. S. (2007). Professor de Química: formação, competências/ habilidades e posturas. Disponível em http://www.ufpa.br/eduquim/formdoc.html

Moraes, R., \& Galiazzi, M. do C. (2011). Análise Textual Discursiva. Ijuí: Ed. Unijuí.

Passos, M. M., Oliveira, B. K., \& Salvi, R. F. (2011 ).As Questões de "Matemática e suas Tecnologias" do "Novo ENEM": um olhar com base na Análise de Conteúdo. Educ. Matem. Pesq., 13(2), 313-335.

Pacheco, D., Megid Neto, J., \& Curado, M. C. C. (1996). Vestibular, Pesquisa Acadêmica e Ensino de Física no nível médio: existe integração? Pró-Posições, 7(1), 58-66.

Portaria Normativa no. 4, de 11 de fevereiro de 2010. (2010). Dispõe sobre certificação de conclusão do ensino médio ou declaração de proficiência com base no Exame Nacional do Ensino Médio - ENEM. Diário Oficial da União. Brasília. 
Resolução CEB n. 3 de 26 de junho de 1998. (1998). Diretrizes Curriculares Nacionais para o Ensino Médio.

Resolução CEPE No 0102/2009. (2009). Fixa Normas e Vagas para o Processo Seletivo Vestibular para ingresso nos Cursos de Graduação da Universidade Estadual de Londrina, UEL.

Resolução CEPE No 0250/2009. (2009). Fixa Normas e Procedimentos para o Aproveitamento da nota do Resultado final do Exame Nacional do Ensino Médio - ENEM no Processo Seletivo Vestibular 2010 da UEL, UEL.

Ribeiro Netto, A. (1985, Dezembro). O vestibular ao longo do tempo: implicações e implicâncias. Trabalho apresentado no Seminário sobre "Vestibular Hoje" MEC/ SESU/CAPES, Brasilia.

Schneider, M., Rostirola, C., \& Mozz, G. (2011). Entrevista com a professora doutora Sandra Zákia Sousa: avaliações em larga escala e os desafios da qualidade educacional. Roteiro, Joaçaba: UNOESC, 36(2), 309-314.

Vianna, H. M. (2003). Avaliações nacionais em larga escala: análises e propostas. Revista Estudos em Avaliação Educacional, 27, 41-76.

Werle, F. O. C. (2010). Avaliação em Larga Escala: Foco na Escola. Brasília: Líber Livro. 
Fabiele Cristiane Dias Broietti

(ㄱ) http://orcid.org/0000-0002-0638-3036 Universidade Estadual de Londrina

Departamento de Química Londrina, Brasil fabieledias@uel.br

Ourides Santin Filho

${ }^{0}$ http://orcid.org/0000-0001-5128-5390

Universidade Estadual de Maringá

Departamento de Química Maringá, Brasil osantin@uem.br

Marinez Meneguello Passos

() http://orcid.org/0000-0001-8856-5521 Programa de Pós-Graduação em Ensino de Ciências e Educação Matemática Universidade Estadual de Londrina Londrina, Brasil marinezmp@sercomtel.com.br

Submetido em 27 de Setembro 2015 Aceito em 22 de Fevereiro 2017 Publicado em 30 de Abril de 2017 